\title{
O POBRE EXCESSO DA LINGUAGEM: A POESIA SEM QUALIDADES DE MANUEL DE FREITAS
}

\author{
Ana Beatriz Affonso Penna ${ }^{1}$
}

RESUMO: Este trabalho está preocupado em discutir a noção de valor na poesia de Manuel de Freitas, atrelando-a à análise de aspectos de sua linguagem poética. Em uma sociedade repleta de qualidades mercadológicas, em que a linguagem é intersectada por diferentes discursos (como os da publicidade, política e economia), Manuel de Freitas propõe poetas sem qualidades. Dessa maneira, o principal objetivo deste trabalho é pensar como a ideia de qualidade, apresentada na obra crítica de Freitas, manifesta-se em sua poética.

PALAVRAS-CHAVE: Manuel de Freitas; poesia portuguesa contemporânea; valor.

\section{THE POOR EXCESS OF LANGUAGE: MANUEL DE FREITAS' POETRY WITHOUT QUALITIES}

ABSTRACT: This work is concerned with discussing the notion of value in Manuel de Freitas' poetry, relating it to aspects of its poetic language. In a society full of market qualities, where language is intersected by many different discourses (such as the ones from publicity, politics and economy) Manuel de Freitas proposes poets without qualities. Thus, the main purpose of this study is to think how the idea of quality, presented in Freitas' critical work, is expressed in his poetics.

KEYWORDS: Manuel de Freitas; contemporary portuguese poetry, value.

\footnotetext{
${ }^{1}$ Ana Beatriz Affonso Penna é mestre em Estudos de Literatura pela Universidade Federal Fluminense.
} 
Em Palestra sobre lírica e sociedade, Theodor W. Adorno inicia sua fala apontando para o provável desconforto de seus ouvintes diante de uma análise da lírica sob um viés sociológico. Ainda que Adorno reconheça que parte possível desse desconforto advém do temor dos críticos e teóricos à abusiva tomada das composições líricas como objetos de demonstração de teses sociológicas, esse identifica como principal causa do incômodo de seu público a ameaça de um olhar que, ao desvelar o caráter social da lírica, pudesse desvanecer sua frágil existência (ADORNO, 2003, p. 65). A lírica, cujo ideal, em um sentido tradicional, pretendeu resguardar-se da engrenagem da sociedade (idem), ao negar se contaminar com o peso da objetividade, ofereceria uma possibilidade de transcender a realidade dura dos dias através de uma linguagem pura que se afasta da manifestação social do mundo. Tal visão, que privilegia a poesia enquanto bálsamo do mundo, ignora o caráter duplo da linguagem estipulado por Adorno, uma vez que a linguagem, ao mesmo tempo em que, através de suas configurações, serve aos impulsos subjetivos, estabelece uma evidente referência à sociedade: "Não apenas o indivíduo é socialmente mediado em si mesmo, não apenas seus conteúdos são sempre, ao mesmo tempo também sociais, mas sim inversamente também a sociedade configura-se e vive apenas em virtude dos indivíduos, dos quais ela é a quintessência” (ibidem, p. 76).

Assim, para Adorno, o poema não é apenas expressão de emoções e experiências individuais, mas, para que essas sejam verdadeiramente composições de arte, devem expressar o geral através de sua forma artística. Essa generalidade do conteúdo lírico, que é essencialmente social, precisa recorrer ao que existe de compartilhável na experiência humana do sensível, de modo que haja a compreensão de suas formas por uma linguagem e vivência sócio-histórica comuns.

Em uma sociedade individualista e, em última análise, atomística, Adorno considera a lírica tradicional como um discurso capaz de explorar a sensação de uma universalidade harmônica e não fragmentada (ADORNO, op. cit., p. 67). Contudo, quanto mais as composições líricas apartam o resíduo da existência convencional e objetiva, mais essas cristalizam os sedimentos da relação histórica do sujeito com a sociedade, uma vez que é o espontâneo, aquilo que não é simples consequência das relações sociais vigentes em dado momento, que captura as badaladas do tempo histórico (ibidem, p. 72-73). O eu lírico, que não mais pode se integrar à natureza - símbolo maior de unidade - ao mergulhar no próprio eu ou ao recorrer a uma espécie de animismo, visaria o restabelecimento de uma união não mais possível. O seu tempo, que já não é o das estações do ano, das colheitas, 
em suma, do momento em que a produção agrária era o trabalho principal, perde seu aspecto cíclico para tornar-se o tempo em linha reta da economia burguesa. De modo que, em poesia, a referência ostensiva a motivos naturais, a criação de um mundo abrigado na subjetividade, a suspensão do tempo pela palavra poética, assim como a defesa de uma linguagem não corrompida pelo seu meio social são sintomas de uma sociedade que sofre com um processo de mudança de paradigmas:

Essa exigência feita à lírica, a exigência da palavra virginal, é em si mesma social. Implica o protesto contra uma situação social que todo indivíduo experimenta como hostil, alienada, fria e opressiva (...). Em protesto contra ela, o poema enuncia o sonho de um mundo em que essa situação seria diferente. A idiossincrasia do espírito lírico contra a prepotência das coisas é uma forma de reação à coisificação do mundo, à dominação das mercadorias sobre os homens, que se propagou desde o início da Era Moderna e que, desde a Revolução Industrial, desdobrou-se em força dominante da vida. (ibidem, p. 69).

Contudo, engana-se quem crê que a lírica tradicional, ao buscar um lugar de integridade em oposição à fratura existente na realidade, estaria instituindo um espaço de real resistência na visão de Adorno. Uma vez que, apesar da poesia que se macula ao contato com a sociedade negar esteticamente os valores da burguesia, essa tem permanecido ligada à sociedade burguesa (ADORNO, op. cit., p. 78) - ora de modo a servir-lhe institucionalmente como um alívio para a maçada a que os dias obrigam, ora como mecanismo de distinção social, constituindo-se privilégio de poucos que tiveram sua sensibilidade devidamente educada. Capital simbólico - "seu falso esplendor é o complemento do mundo desencantado do qual ela se desprende” (ibidem, p. 76).

Na seção final de sua palestra, a fim de exemplificar a relação que o sujeito poético, que é sempre um sujeito coletivo em relação a seu lugar na linguagem e no mundo, mantém com a realidade social, Adorno recorre à análise de dois poemas: o poema Auf einer Wanderung [Em uma caminhada], de Mörike, e a canção do poeta Stefan George, chamada Der Siebente Ring [O sétimo anel]. No poema de Mörike, a imagem da promessa de felicidade em um idílio da cidade pequena é acoplada ao estilo elevado da obra, de forma "a unificar artisticamente a utopia da proximidade mais próxima com a da mais extrema distância" (ADORNO, op. cit., p. 81-82). Mörike, que magistralmente, repercute as reminiscências do estilo elevado, junto com as marcas da felicidade das coisas próximas, soube compor imagens que "não se traem nem pelo requinte do drapeado nem pela vulgaridade da conversa de botequim” (ibidem, p. 83). No entanto, tão frágil equilíbrio entre a grandiloquência do sentimento, da natureza e da linguagem e a miudez da realidade de 
uma pequena cidade e do cotidiano é representativo de um impasse entre sistemas de valor que não mais podem conciliar-se, uma vez que tal solução encontra-se interditada pela tendência histórica (idem).

Já a canção de Stefan George, ao rejeitar o recurso fácil de certas figuras de retórica e a determinados ritmos em favor de uma economia poética, favorecendo a construção de imagens a partir de uma sintaxe elíptica e fragmentada, agiria, para Adorno, de modo a diminuir a distância em relação à linguagem degradada do comércio. Distante de uma poesia que, em sua procura pelos modelos dos menestréis e da epopeia medieval, torna-se grosseiro ornamento, assim como afastada do repertório da lírica do mundo moderno, Der Siebente Ring, resguarda o poema do conformismo pelo seu princípio de estilização. $\mathrm{Na}$ canção, onde predominam versos curtos e abruptos com um vocabulário de raiz concreta, não há espaço para a reconciliação orgânica de elementos conflitantes (ADORNO, op. cit., p. 86), como também não há lugar para uma extensa marcação do sujeito poético.

Aqui, para que o sujeito seja capaz de, em sua solidão, resistir verdadeiramente à reificação, ele não pode nunca mais se refugiar no que lhe é próprio, como se fosse sua propriedade; os vestígios de um individualismo que, nesse meio-tempo, já se entregou à tutela do mercado, nos suplementos literários, assustam: o sujeito precisa abandonar a si mesmo, na medida em que se cala (ADORNO, op. cit., p. 87).

Foco na criação de imagens, experimentação, limpidez formal, rarefação, fragmentação irregular da sintaxe, concisão e despersonalização. As características que Adorno atribui como causas do inconformismo da canção de Stefan George são muito similares às de poéticas atacadas por Manuel de Freitas no prefácio da antologia Poetas sem qualidades (2002), coletânea que reunia uma seleção de poemas de nove autores contemporâneos e instaurava um embate no panorama da poesia portuguesa mais recente. "A um tempo sem qualidades, como aquele em que vivemos, seria no mínimo legítimo exigir poetas sem qualidades" (FREITAS, 2002a, p. 9) - anuncia Freitas na sentença de abertura do prefácio $O$ tempo dos puetas. Figura central de um conjunto de poetas que começam a publicar, sensivelmente, na década de 90, a poética de Freitas, a qual defende uma relação da lírica com o seu próprio tempo, aponta para uma dimensão social da vida e linguagem cotidianas, assim como para uma resistência a uma sociedade reificada.

Manuel de Freitas admite a poesia enquanto uma realidade histórica (ibidem, p. 14), a qual demanda dos poetas uma responsabilidade estética com o seu tempo. Contra ao que chama de culturalismo autossuficiente (ibidem, p. 13), do qual acusa o renomado poeta Nuno 
Júdice, Freitas propõe uma poesia que manifesta "força - ou admirável fraqueza - onde outros apenas conseguem ter forma ou uma estrutura anémica" (idem). Diferente de Ulrich, do romance inacabado de Musil, "O Homem sem Qualidades”, Manuel de Freitas não se paralisa diante do peso da tradição e da urgência pela originalidade e faz "da novidade um uso menor, nas bordas da ironia" (EIRAS, 2011, p. 22). Ao recuperar os nomes de António José Forte e Joaquim Manuel Magalhães e propor uma nova recepção de poetas já consagrados pela crítica, como é o caso de Herberto Helder, o poeta escolhe uma tradição outra, na qual ancora práticas poéticas que parecem propor um novo regime de valor para a poesia. De modo que, no lugar do poeta monumento, propõe um texto e uma leitura (EIRAS, 2011, p. 18).

O tempo dos puetas, em declarado combate a um fazer poético que exibe um “ostensivo manejo” de 'qualidades' (FREITAS, op. cit., p. 14), ergue-se em oposição a uma prática lírica que tem sua principal matriz no que se convencionou chamar de geração de 61. Contra o poeta ourives de barro que "quase torna palpável o esforço" (ibidem, p. 13) com que elabora o artifício, "pensando certamente num público alargável ao seu génio" (idem), Manuel de Freitas prefere uma poesia em que a articulação do poema enquanto "experiência emocional do mundo" (MARTELO, 2003, p. 46) prevaleça sobre um determinado modo de labor formal que busca uma manifesta expressão depurada e não discursiva.

No entanto, o que parece estar em jogo no que se denomina tensão emocional, no artigo de Martelo dedicado à poesia sem qualidades, é justamente a questão da subjetividade, sendo a poesia de expressão emocional aquela de tradicional enunciação de um eu lírico, claramente marcado no poema, e não o caso de uma poesia de primazia do sentimento - já em uma acepção romântica. A revalorização da enunciação lírica somada à figuração de certa experiência individual e cotidiana de mundo traria aos sem qualidades uma tensão cuja nomeada emotividade, no artigo de Martelo, parece identificar-se com uma visão de emoção enquanto uma articulação mais direta de um eu lírico ao par poema-mundo e não com a noção de força/fraqueza apresentada por Freitas, nem com a expressão de certo transbordamento sentimental. Pois, ainda que a poesia de um Manuel de Freitas seja altamente afetiva nas dedicatórias e referências aos amigos, família e amores, assim como 
intensa em seu confronto eu lírico/poema/mundo ${ }^{2}$, existe, com regularidade em sua poética, uma rarefação retórica e imagética, a qual não permite um transbordamento sentimental ou uma manifestação de força senão em certos momentos chave do poema momentos em que se observa uma maior densidade e tensão retórica e imagética. Tais momentos, os quais coincidem especialmente com os versos finais, como assinala Joaquim Manuel Magalhães ao falar da poesia de Rui Pires Cabral, apontam para "a precisa maestria com que cada poema cresce para o seu fim" (MAGALHÃES, 1999, p. 278). De forma que se observa em Manuel de Freitas, como em Rui Pires, um trabalho para a construção de uma organicidade textual, a qual "exige uma chave final que faça crescer o ritmo das declarações e encerre o poema com qualidade conseguida" (idem).

Fruto de vigilância e labor, tal rarefação retórica e imagética, como afirma Pedro Eiras, "é um trabalho de renúncia à auréola, porque nenhuma auréola se perde de uma vez por todas" (EIRAS, 2011, p. 52). Em embate ao processo constante de recomposição aurática das artes (GUERREIRO apud EIRAS, 2011, p. 52), ergue-se a necessidade de uma poesia à contramão de tantas qualidades que adornam a linguagem poética, embotando-a. Já não mais se trata de "limar as arestas que a vida deveras tem" (FREITAS, 2002a, p. 14), pois o excesso da vida, ainda que "baixo e deselegante" (FREITAS, 2001, p. 11), é agora "uma maneira de dizer ausência" (FREITAS, 2003, p. 55). Importa é limar as auréolas do poema e da vida, em busca de uma linguagem poética que possa dizer seu tempo: fazer sentido. Assim, a prática adotada por Freitas de alternar picos imagéticos e retóricos nos poemas com pequenas descrições e narrativas prosaicas mostra-se, dessa maneira, um trabalho de linguagem que dá forma a uma concepção de poesia que procura, na ausência de qualidades de um tempo e espaço, a emersão do poético, mesmo enquanto resto - o qual, ainda que ingerido, recusa-se a ser completamente absorvido por uma lógica reificadora. Mas permanece a pergunta: estariam realmente tão distantes, a partir de uma visão adorniana, os valores professados pelas poéticas que o autor do prefácio $O$ tempo dos puetas enfrenta, daqueles que o mesmo propõe para uma nova poesia portuguesa?

Como Adorno e o próprio Manuel de Freitas salientam, existe uma indissociabilidade entre tempo e lírica. "Mudam-se os tempos, mudam-se as vontades" (CAMÕES, 1953, p. 178) - já disse o velho vate. De modo que o que antes despontava como linguagem inovadora, inacessível ao alcance de poderes totalitários pela sua

\footnotetext{
${ }^{2}$ Por confronto eu lírico/poema/mundo, entendo o choque entre uma determinada figuração de eu com uma específica figuração de mundo que só pode acontecer através do poema, ou seja, através de uma criação de linguagem, confrontando-se assim também o lugar dessa criação.
} 
radicalidade de escrita, hoje, após um processo de institucionalização, consumo e canonização, soa como regra, necessidade de superação para os novos escritores. Os tempos são outros e a relação com a poesia e a linguagem também é outra. E não é em vão que Pedro Eiras afirma que "a poesia que descreve a pobreza não é forçosamente pobre mas decerto também não é rica" (EIRAS, 2011, p. 187).

Se no Iluminismo observava-se o otimismo e o esforço dos intelectuais por estabelecer a ciência objetiva, a moralidade e as leis universais, na Modernidade tardia a crença que tudo estaria ao alcance da razão apresenta-se severamente enfraquecida. Após duas guerras mundiais, constatou-se que os progressos científicos e técnicos não acabariam com o sofrimento humano. A ideia de subordinação dos interesses particulares para atingir o bem público tornou-se uma ameaça à liberdade humana, que com olhares de suspeita passou a enxergar o projeto modernizador iluminista como um possível sistema de opressão universal (HARVEY, 1992, p. 23). Assim, marcada pela desconfiança e descrença no cumprimento das promessas modernas, a era em que os poetas sem qualidades escrevem é a do movimento de reificação do capitalismo tardio, que se expande a domínios imagináveis. Abalados em sua fé na potência da palavra poética no mundo, os poetas sem qualidades reconhecem os limites de ação de sua poesia enquanto uma prática social que partilha de um lugar muito específico nas maneiras de ver e fazer de uma determinada estrutura social.

Ciente de seu lugar de "um discurso entre discursos" (EIRAS, op. cit., p. 187), a lírica dos sem qualidades que, decerto diferencia-se do "discurso do turismo, da cultura, da mercadoria inconsciente de si própria" (idem), não mais pode escapar à consciência de sua circunscrição no reino das mercadorias - ainda que um capital simbólico menos lucrativo por seu escasso consumo e políticas de difusão. A experiência da mercantilização da escrita, como da maior parte das vivências, são questões que agora, necessariamente, têm que ser incorporadas à própria tessitura do texto, para além de uma recorrência temática:

Outros haverá, escrevendo melhor

ou pior e obedecendo ou não

à falsa mas inescapável urgência

do verbo. Que sei eu? São mundos

sobrepostos, detritos, discursos

inconciliáveis. À imagem dos graffiti

que crescem junto à linha do comboio, ameaçando a pacatez deste bairro.

(FREITAS, 2002b, p. 66). 
Assim, para evitar a condescendência da poesia, o poeta precisa encarar a nudez da vivência e linguagem massivas. Ele chama a linguagem prosaica, de uma sociedade de mercado, para o poema, a fim de superar sua alienação, tornando-a perceptível. Uma vez que, ao deslocá-la do seu uso comum para um ambiente em que seu comparecimento é inadequado, o poeta promove um estranhamento, força a linguagem lisa da comunicação tradicional, imbuída de um aparente excesso de literalidade, a mostrar suas dobras.

De acordo com Blanchot, toda linguagem aponta para um vazio, uma vez que ela representa aquilo que deixou de estar presente. De modo que nomear é assassinar um objeto em sua presença total em favor de um conhecimento sobre o mundo - o qual só pode estabelecer-se enquanto precário, já que nome e objeto não são coincidentes (BLANCHOT, 1997, p. 323). Assim, há sempre entre a linguagem e a presença uma sobra, um resíduo, elementos e relações excluídos por um nome ou sintaxe. O que leva a crer que Manuel de Freitas, ao trazer à pena aspectos da fala prosaica, esteja interessado em ativar a potência dos restos inauditos pela alienação cotidiana, entrecruzando-os com recursos de uma experiência formalizante da poesia.

Em sua descrição dos filmes de série B, Pedro Eiras atenta para os efeitos de um excesso de imagens característico de filmes comercias: "um fluxo demasiado rápido e carregado de informações para ser interpretado, demasiado fugaz para permitir uma experiência ontológica do mundo" (EIRAS, 2011, p. 152). Inevitáveis, esses filmes são parte do acervo imagístico dos poetas sem qualidades, figurando sincreticamente ao lado de produtos culturais mais elevados em seus poemas. Repletos de uma "acção e um kitsch prontos a consumir" (idem), são instauradores de uma sensibilidade própria, apoiando-se em uma recepção distraída (idem). De modo que do emaranhado de cenas consumidas por um movimento involuntário, por vezes, alguma imagem salta aos olhos. Essa imagemresíduo, tal qual uma pedra no caminho das projeções luminosas, faz soar uma potência que apenas se revela quando agenciada por uma subjetividade. Assim como a linguagem cotidiana, em seu fluxo acrítico, as imagens dos filmes hollywoodianos são deslocadas para uma pausa possível que constitui o poema.

Em "Benilde ao balcão 2", a imagem do jogo de xadrez contra a morte em $O$ sétimo selo, de Bergman, é convocada no poema para dizer da inadequação da vida às cenas grandiosas do cinema: "Não jogamos xadrez,/ nem sequer dominó - isto não é/ Bergman, é apenas a vida (?), pouco dada a estéticas.” (FREITAS, 2001, p. 29). Se agora é permitida à série B figurar nos poemas, os filmes de arte, que antes poderiam ter livre circulação entre 
as referências líricas, são forçados a um uso menor: uma leitura que busca algo além de suas reconhecidas qualidades.

Interrompido o circuito alienante, palavras e imagens da tradição, ou dela exclú́das, podem ser interrogadas, ousar novas repercussões, sem, contudo, deixarem apagar o seu lugar originário, caindo mais uma vez em uma espécie de alienação pelo sublime. Pois é preciso vigilância para não recompor a carga aurática da poesia; para deixar em aberto uma ferida que é uma necessidade ética: "a cicatriz pungente de um tempo que é nosso" (FREITAS, 2002a, p. 13). A poética de Manuel Freitas não está disposta a conciliações, a propor o prosaico como novo recurso à elevação, ela quer antes perpetuar desconfortos. É somente estabelecendo o desacordo entre os parâmetros para o poético e obra poética que Freitas força, tanto a crítica literária como o mercado, a repassarem seus pressupostos e linguagem, que de outra forma, permaneceriam implícitos. Agora, o que antes era alvo de combate - a corrupção da lírica pelo social - torna-se reivindicação programática no prefácio e poesia de Freitas.

No poema "Zulmira ao amanhecer", de Os Infernos Artificiais, publicado em 2001, encontramos uma enunciação diretamente proveniente da linguagem relativa à sociedade de consumo. "No urinol público lia-se UTILIZAÇÃO GRATUITA”" (FREITAS, 2001, p. 21) - assim começa o poema dedicado a Zulmira e sua taberna. Quase feliz por encontrar algo livre de um valor monetário - "(quantas coisas gratuitas/ há neste mundozinho de horror?)" (idem) - o eu lírico segue da observação do aviso à descrição dos seus dias na taberna:

No urinol público lia-se UTILIZAÇÃO GRATUITA.

Fiquei quase feliz (quantas coisas gratuitas há neste mundozinho de horror?).

Mas o que desta manhã eu mais agradeço, Zulmira, é a tua sopa, essa que tantas vezes me salvou a vida, entre centenas de super bocks.

Não me inquietam os chulos, os assassinos ou estes mendigos calados. Ilustríssima gente, de uma má-raça inegável. Prefiro perder com eles os meus dias, e falar da fome, dos joanetes ou do preço do azeite. Não tenho tempo para aprofundar desrazões, nem para conviver com puetas.

Sei apenas que as poucas pessoas que amei estavam por detrás de um balcão onde o álcool ardia, muito devagar. Os meus pobres anjos.

Também por isso gostava de te obrigar a esta taberna, 
exílio cantante de todas as minhas antigas manhãs.

Por esta mãe desolada, pelo rumor sombrio do vinho que nunca azedou nos meus lábios, por certas inábeis palavras que sobre os barris faleceram e te pertenciam somente.

Mas «até logo, Zulmira», bem sabes que do amor ou do futebol nada poderei jamais dizer ou sentir. Entre os teus braços largos deponho em silêncio aquela negra noite do meu mal. Por uma sopa encorpada, sobre destroços imperecíveis, bocados de morte partidos. (FREITAS, op. cit., p. 21)

O urinol, que mesmo sendo um objeto 'baixo' necessita ser anunciado como gratuito, caso contrário se depreenderia que não o seria, também é nome da seção em que se insere o poema. Objeto pilar na polêmica exposição dadaísta de 1920, a qual estava interessada em problematizar os paradigmas e valores nas quais a arte se sustém, o urinol, antes renegado a figurar enquanto matéria de arte, agora, em "Zulmira ao amanhecer" representa um dos raros espaços em que o dinheiro não é chancela para o seu uso. O aviso “UTILIZAÇÃO GRATUITA”, cuja violência irrompe no poema pela inicial inadequação de um enunciado deste formato em um texto lírico, ao mesmo tempo em que denuncia o processo de mercantilização, caracteriza-se como ponto de partida para a reflexão do sujeito sobre uma experiência afetiva. A gratuidade das coisas baixas, como a do urinol e dos amigos “(...) chulos, os assassinos/ ou estes mendigos calados. Ilustríssima gente,/ de uma má-raça inegável.", é afirmada enquanto um valor maior. Mas não esqueçamos que 'gratuito’ é também, conforme definição no Dicionário Houaiss de Língua Portuguesa, algo desinteressado, espontâneo, que não tem fundamento. Assim, por trás da literalidade do aviso, vê-se ressoar um significado outro. $\mathrm{O}$ amor dedicado às pessoas que "estavam por detrás de um balcão", seus "pobres anjos", que é espontâneo, desinteressado e não tem fundamento, é gratuito como o urinol. Contudo, sem fundamento e gratuita é também a morte, a qual se manifesta semanticamente várias vezes no poema através das figuras e expressões “assassinos", "pobres anjos", "salvar a vida", "até logo" e o verbo "falecer". De modo que, assim como a espontaneidade da relação não anula o fundamento da morte, a gratuidade do urinol não o redime de uma lógica reificadora. Manuel de Freitas, diferente dos “meerceiros do sublime" (FREITAS, 2002b, p. 71), não transubstanciará a urina em vinho. 
Já o poema "All stripped down", de título homônimo ao da canção do disco The Heart of Saturday Night de Tom Waits, utiliza o modelo de um classificado da seção de relacionamentos para alicerçar seus sentidos:

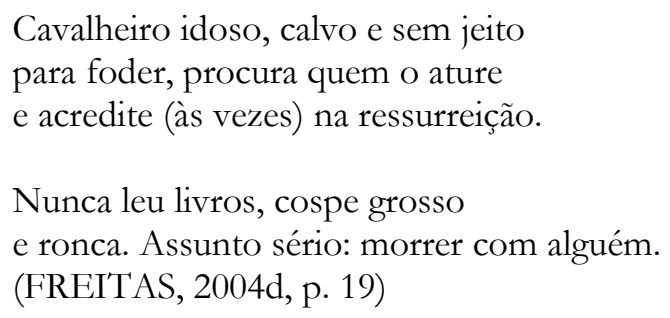

A expressão strip down, que significa no inglês 'despir-se', na música de Waits, situase no contexto do dia do juízo final, momento em que os homens despojam-se completamente de quaisquer máscaras sociais. Assim, o sujeito que se anuncia no poema enquanto matéria disponível a afetos, ao optar por uma descrição abrupta e impiedosa dos caracteres que compõem sua subjetividade, choca-se com o modelo padrão, ao qual nos habituamos a ver nos classificados. O que sugere que entre anúncio e realidade existe um desnível. Um desnível que é o da propaganda e a pessoa anunciada, a qual exibe sua condição mercadológica no uso objetificador da terceira pessoa do singular, mas também o desnível que é inerente ao ato representativo. "Cavalheiro idoso, calvo e sem jeito / para foder (...)" sinaliza tanto a quebra de uma promessa mercadológica que se realiza através de uma construção de linguagem, como também um resíduo inaudito nas palavras dos usuais anúncios. E é a morte, mais uma vez, o horizonte - ou ausência de um - que desvela esses dois movimentos. A morte física que se aproxima do sujeito pelos seus longínquos anos, fazendo-o não mais se importar com vãs aparências, e a morte realizada pela palavra através da ausência daquilo que foi ou é presença total.

Em "Retrato de Helena de Tróia jogando flippers na Rua Misericórdia", o movimento observado nos dois últimos poemas analisados inverte-se: agora é a vez de Helena, elemento clássico, penetrar no tecido do poema, irradiando sobre sua linguagem uma nova luz:

Gosto de vir a este café todas ou quase todas as terças à tarde, sobretudo se chover.

Não conheço sítio melhor para se ler (vamos supor) a Iliada - entre putas, semi-putas e putas antigas. Qualquer uma delas poderia dizer, como Helena, "sou uma cadela" - de um modo resoluto, desinibido e mais cheio de graça (para ser inocente só é preciso inocência).

Mas tantas vezes o que me acontece é fechar 
o livro, ficando a ouvi-las vociferar,

discutir sem rancor e com um gentil acento

metafísico temas prementes como o sexo (infalível),

as rendas de casa ou tragédias de lavandaria.

Um jogo de flippers bastar-lhes-á depois para matar o tédio

De quando as palavras se negam ou as telenovelas demoram.

E é isto que me apetece achar belo, desesperante.

(...)

(FREITAS, 2001, p.13)

Helena, a mais bela entre as mulheres, é posta ao lado de "putas, semi-putas/ e putas antigas", as quais como ela poderiam dizer "sou uma cadela". No entanto, importa atentar que é Helena a cadela primeira, com as quais as putas podem se equiparar. O que significa dizer que o rebaixamento de Helena não se dá em função da sua aproximação com o espaço indecente, uma vez que já estava no clássico, ainda que encoberto, o seu 'desvio'. Desvio o qual as camélias realizam "de um modo/ resoluto, desinibido e mais cheio de graça”, já que “(para ser inocente só é preciso inocência)". De maneira que a afirmação daquilo que escapa a uma ótica moralista, grandiloquente e conservadora, é no poema valor, beleza. Podem dizer as putas de modo mais resoluto, pois a elas lhes sobra inocência - pura - e não um artifício que a simula. Ouso: para ser inocente só é preciso inocência e não qualidades. "E é isto que me apetece achar belo, desesperante". Helena precisa dar passagem a suas companheiras.

À metáfora, símbolo maior da linguagem poética, Manuel de Freitas cede a contragosto. Figura de linguagem que trabalha com os traços semânticos comuns entre duas ideias, estabelecendo-se então um terceiro termo, a metáfora atribui a um referente algo que inicialmente não lhe diz respeito, transfigurando imagens por meio de comparações implícitas ${ }^{3}$. Tal processo de transfiguração da palavra comum, quando associado a um projeto aurático de transubstanciação da realidade em prol do esplendor da poesia $^{4}$, é visto por Freitas como uma “(...) baba quente e desajustada/ sobre os ombros onde um cancro sonha” (FREITAS, 2002c, p. 8). Pois, como aponta Luís Miguel Queirós, “ $[u] m$ tempo tão raso, tão, digamos, mortiço, como este em que Freitas se sente sobreviver, não pede metáforas fulgurantes, nem, decerto, 'obras'. De modo que a metáfora em Freitas precisa ser atenuada: '(...) Acordei com esse verso,/ abri a porta ao nevoeiro (é uma/

\footnotetext{
${ }^{3}$ Em síntese - didática -, pode-se definir a metáfora como a figura de significação (tropo) que consiste em dizer que uma coisa (A) é outra (B), em virtude de qualquer semelhança percebida pelo espírito entre um traço característico de A e o atributo predominante, atributo por excelência, de B, feita a exclusão de outros, secundários por não convenientes à caracterização do termo A (GARCIA, 2001, p. 107).

${ }^{4}$ Por esplendor da poesia, refiro-me à expressão utilizada por Adorno: "seu falso esplendor é o complemento do mundo desencantado do qual ela se desprende" (ADORNO, 2003, p. 76).
} 
observação meteorológica)" (FREITAS, 2007b, p. 15). O "nevoeiro", que é uma metáfora, quando situado apenas como "uma observação meteorológica", pelo irônico comentário do sujeito poético, já não pode mais manter sua figuração plena. A metáfora, agora, é um grito que se enuncia sem poder ser berrado:

O corpo já quase não responde a tanta tristeza. E a casa, devagar, fecha-se para dentro, implode. Parece um coração, uma metáfora que te deixa nos ombros um irrepetível cheiro a merda e a sombra de um gato que vai morrer. (FREITAS, 2002b, p. 68) 


\section{BIBLIOGRAFIA}

ADORNO, Theodor. Palestra sobre lírica e sociedade. In: Notas de Literatura I.

Trad. Jorge Almeida. São Paulo: Duas Cidades/Ed. 34, 2003.

BLANCHOT, Maurice. A parte do fogo. Trad. Ana Maria Scherer. Rio de Janeiro: Rocco, 1997.

CAMÕES, Luís de. Rimas. Edição de Álvaro Júlio da Costa Pimpão. Coimbra: Atlântida, 1953.

EIRAS, Pedro. Um certo pudor tardio. Ensaio sobre os "poetas sem qualidades". Porto: Edições Afrontamento, 2011.

FREITAS, Manuel. Os Infernos Artificiais. Lisboa: Frenesi, 2001.

. “O tempo dos puetas”. Poetas sem Qualidades. Lisboa: Averno, 2002a.

- [Sic]. Lisboa: Assírio \& Alvim, 2002b.

. Game Over. Lisboa: \& etc, 2002c.

. Beau Séjour. Lisboa: Assírio \& Alvim, 2003.

. O coração de sábado à noite. Lisboa: Assírio \& Alvim, 2004.

Terra Sem Coroa. Vila Real: Teatro da Vila Real, 2007.

GARCIA, Othon Moacir. Comunicação em prosa moderna: aprenda a escrever, aprendendo a pensar. 20 ed. Rio de Janeiro: Editora FGV, 2001.

HARVEY, David. Condição pós-moderna: uma pesquisa sobre as origens da mudança cultural. 5 ed. São Paulo: Loyola, 1992.

MAGALHÃES, Joaquim Manuel. Rima Pobre. Barcarena: Editorial Presença, 1999.

MARTELO, Rosa Maria. "Reencontrar o leitor". Relampago. Lisboa: Fundação Luís Miguel Nava, n 12 , abril/2003.

\section{Artigo recebido em 30 de Março de 2013.}

Artigo aprovado em 20 de Maio de 2013. 